\title{
EL PLAN DE VIDA DE LOS PUEBLOS INDÍGENAS DE COLOMBIA, UNA CONSTRUCCIÓN DE ETNOECODESARROLLO
}

\author{
Jhon Jairo Monje Carvajal $^{1}$
}

Recibido el 12 de marzo de 2014, aprobado el 1 de octubre de 2014 y actualizado el 27 de abril de 2014

DOI: 10.17151/luaz.2015.41.3

\section{RESUMEN}

La realidad sobre los derechos formales de los indígenas sobre los territorios colectivos, dista mucho de estar ajustada a la que plantea la Constitución Política de Colombia respecto a la calidad de vida y en el cumplimiento de su derecho de autonomía. Permanecen todavía graves problemas que atentan contra sus territorios, la tranquilidad, la paz y su pervivencia. El casi nulo cubrimiento de necesidades básicas como salud, educación, alimento y vivienda por la no inclusión en los planes de desarrollo municipales de estas comunidades, bajo el argumento de que sus territorios reciben sus propios recursos económicos, amenaza la sobrevivencia de estos grupos y convierte sus territorios en zonas de guerra, de conflicto y de intereses particulares. Esto se refleja en la realidad nacional y no existe ni social ni políticamente la conciencia de que esto constituye un hecho de discriminación racial. Se plantean entonces alternativas metodológicas de cómo construir planes de vida más ajustados a su realidad con muchas alternativas para la cohesión de estas comunidades indígenas con los planes de desarrollo de los municipios que contienen dichos territorios colectivos; que se construyen luego de un análisis profundo desde una perspectiva diferente a modelos económicos desde sus propios momentos de vida, con un proceso de construcción más ajustado a sus culturas, realidades tanto ambientales como sociales en sus territorios. El resultado es una serie de estrategias que sería hasta ahora un abordaje más ajustado a dichas realidades, desde los planteamientos de la agroecología hacia la aproximación de lo que sería el etnoecodesarrollo.

\section{PALABRAS CLAVE}

Planes de vida, etnoecodesarrollo, desarrollo endógeno, saber ancestral, agroecología, momentos de un plan de vida.

\section{COLOMBIAN INDIGENOUS PEOPLES‘ LIFE PLAN, A STRUCTURE OF ETHNO-ECO DEVELOPMENT}

\section{ABSTRACT}

The reality on the formal rights of indigenous people on collective territories is far from being adjusted to what is set out by the Constitution of Colombia regarding quality of life and fulfillment of their right to autonomy. Serious problems that threaten their 
territories, tranquility, peace and survival still remain. The almost non-existent coverage of basic needs like health, education, food and shelter due to the lack ot inclusion in the municipal development plans of these communities, with the excuse that their territories are given their own economic resources, threaten the survival of these groups and turn their territories into war, conflict and individual interests zones. This is reflected in the national reality and neither social nor political awareness exist that this is an act of racial discrimination. Methodological alternatives on how to build life plans tighter to their reality with many alternatives to the cohesion of these indigenous communities in the formulation of municipalities development plans containing such collective territories then arise, which are constructed after a deep analysis from a perspective different to economic models derived from their own life moments with a construction process tighter to their cultures, both environmental and social in their territories. The result is a series of strategies that would be, so far, a tighter approach to such realities, from agroecology approaches to an approximation of what would be the ethno-eco development.

\section{KEY WORDS}

Life plans, ethno-eco development., endogenous development, indigenous knowledge, agroecology.

\section{INTRODUCCIÓN}

En Colombia 1'378.884 habitantes son indígenas, lo cual corresponde al 3,4\% de la población total del país (DANE, 2005). Están localizados en 710 resguardos $^{2}$, esto es, 228 municipios de 27 departamentos (DANE, 2005). Sus procesos de organización y lucha, que datan de la época de la conquista, han tomado mayor fuerza y coherencia en los últimos 20 años en los que se han consolidado organizaciones de diverso orden con fines reivindicativos y de autogestión bajo los principios de unidad, territorio, cultura y autonomía.

La Constitución de 1991 reconoce y protege la diversidad étnica y cultural de la nación colombiana (CPC, art. 7). Consagra para estas comunidades derechos étnicos, culturales, territoriales, de autonomía y participación, tales como: la igualdad y dignidad de todas las culturas como fundamento de la identidad nacional, las diferentes lenguas que se hablan en nuestro país como lenguas oficiales en sus territorios, la educación bilingüe e intercultural para los grupos étnicos y la doble nacionalidad para los pueblos indígenas que viven en zonas de frontera (CPC, arts. 10 y 96).

La diversidad regional, étnica y cultural que definieron para el país "la Nación multiétnica y pluricultural", dio paso a la utilización generalizada de los términos que hoy día han ganado un espacio en la sociedad colombiana; es decir, una nación más acorde con la realidad y más compatible con la ética universal y humanista 
de los principios que dan origen a las sociedades democráticas y participativas.

Esto tenía que ser así; las referencias se dan al revisar lo que pasó a partir del 12 de octubre de 1492: la introducción de nuevas plantas y animales llegados con los europeos, la inserción de pueblos europeos y africanos con sus juicios, prácticas culturales y tradiciones típicas de sus conocimientos, y que al final alteró los ecosistemas existentes hasta ese momento en las nuevas tierras, sus estructuras sociales y culturales (Fals Borda, 1975).

Pero no solo fue la mezcla o introducción de nuevas especies, razas, etc. Se dan cambios importantes en las actividades normales para los indígenas, para cumplir con las labores a las que los sometieron los colonizadores; inicialmente fueron obligados al trabajo por la extracción de metales, y posteriormente por el usufructo de la tierra (Fals Borda, 1974). Fue de esa manera como se dio inicio a un proceso modificador, destructivo y acelerado de gran parte de los equilibrios en el continente americano, los cuales a la naturaleza y a los indígenas les había tomado muchos años establecer.

De toda esta influencia externa en América, la zona que es hoy Colombia se representa como una de las mayores receptoras y fácilmente se puede ver en la población nacional. Los datos del Gobierno nacional determinan la existencia:

[...] de 87 etnias indígenas ${ }^{3}$, tres grupos diferenciados de población afrocolombiana y el pueblo ROM o gitano. Se hablan 64 lenguas de origen amerindio; lenguas afrodescendientes como el bandé, que es lengua de los raizales del archipiélago de San Andrés, Providencia y Santa Catalina; el palenquero, lengua criolla de las comunidades de San Basilio de Palenque primer pueblo negro libre de América y declarado por la UNESCO como obra maestra del patrimonio oral e inmaterial de la Humanidad-, y la lengua Romaní o Romanés de los pueblos gitanos. (DANE, 2000, p.9)

Hoy, los indígenas colombianos plantean de nuevo la posibilidad de que se establezca una convivencia multiétnica y pluricultural solidaria con la construcción de un proyecto nacional autónomo. La Constitución de 1991 que les otorgó la posibilidad de ocupar cargos públicos de elección nacional, llevó a que congresistas indígenas presentaran en 2003, ante la Cámara de Representantes del Congreso de la República, un proyecto de Acto Legislativo que buscó adicionarle al artículo 339 de la Carta Política (referido al Plan Nacional de Desarrollo) un inciso para que los pueblos indígenas y los grupos étnicos en general puedan elaborar y adoptar dentro de su ámbito territorial planes de desarrollo y planes de ordenamiento territorial, acorde con sus usos, costumbres y valores culturales propios. 
Este marco de derechos formales dista mucho de ser una realidad para las comunidades en lo que a calidad de vida se refiere y en el cumplimiento de su derecho de autonomía en su territorio. Persisten en ellas graves problemas como la usurpación de sus territorios por colonos, terratenientes y otros "grupos sociales" que atentan contra la tranquilidad, la paz y su pervivencia.

Un ejemplo claro de esto son las comunidades indígenas de la costa Pacífica en Colombia; especialmente las comunidades del departamento de Chocó, que aun siendo una región de incalculable riqueza en recursos naturales, han visto afectadas sus vidas con la creciente presencia de grupos armados que sostienen una confrontación por el control de territorios, por la producción y la transformación de cultivos de uso ilícito, asentando sus tropas y alimentando el clima de guerra. Incluso, en los últimos años ha sido notable la aparición de nuevos "actores sociales" que hacen de la región un espacio para el desarrollo de actividades económicas legales o ilegales.

Pero el desplazamiento no responde solo a lógicas de guerra, también está asociado a intereses económicos que son menos visibles a medida que se intensifica el conflicto armado. Hay conexiones entre el desplazamiento y el desarrollo de megaproyectos casi siempre relacionados con el uso intensivo de recursos naturales. En efecto, la mayor parte de las personas son desplazadas de regiones en las que hay iniciativas agroindustriales, de macroproyectos, de obras de infraestructura.

El reconocimiento a la diversidad étnica y cultural de la Nación, por lo reciente y novedoso, no ha sido asimilado en su totalidad ni por la sociedad nacional ni por las instituciones del Estado y menos aún por los grandes empresarios, quienes no han podido entender que las relaciones Sociedad-Estado-Capital deben ser construidas por ambos dentro de unos parámetros de respeto, equidad, justicia y solidaridad. En este sentido es importante analizar que los pueblos indígenas en Colombia siguen siendo altamente vulnerables, sin desconocer lo fuerte y consolidado de sus procesos organizativos.

Las transformaciones que se están viviendo, los cambios sociales, el uso de la tierra y los recursos naturales alteran profundamente la cultura local, los patrones de consumo, las prácticas productivas y las condiciones de vida de las comunidades indígenas que se encuentran en sus zonas de vida. Hoy, es común el abandono de aquellas formas tradicionales de reproducción, tanto de la vida física como de la social y la espiritual de estas comunidades; parece que este proceso favorece la creciente tendencia a que cientos de familias por diferentes razones, abandonen sus posesiones y emprendan un largo camino hacia un destino aún más incierto: la ciudad.

Es por eso la estructuración de un plan de vida, que permita rescatar algunos de los más profundos conocimientos tradicionales desvanecidos en el tiempo y mermados en el espacio por actores antes mencionados. De ahí, que el papel de 
la familia y los componentes de la misma en su función de desarrollo comunitario son importantes para realizar un estudio desde la agroecología. Los pueblos indígenas han demostrado históricamente que poseen los conocimientos ancestrales necesarios para la pervivencia del mundo entero, su aporte en los actuales momentos de calentamiento global y cambio climático, resulta esencial.

Así se sustenta una propuesta investigativa para demostrar, por intermedio de un proceso de investigación acción participativa, cómo un plan de vida indígena construido, planificado, estructurado y presentado por las propias comunidades indígenas puede ser la base de su etnoecodesarrollo, generando estructuras de resistencia a la modernidad y en muchos de los casos, a estructuras de resiliencia, per se a sus principios y a las conquistas fallidas de la cultura occidental neoliberal; en propuestas de identidades, perfiles, modas y estilos de vida a los que ellos no están dispuestos a ser inmersos todavía; pero que tampoco sería de utilidad si se mantienen los perfiles de violación permanente del precepto de autonomía que les otorga a las comunidades indígenas la Constitución Política del país.

\section{LA RAZÓN DEL ETNOECODESARROLLO}

Las argumentaciones epistemológicas sobre la consideración de este concepto como una definición integradora tienen raíz en los análisis que se hacen de los diferentes conceptos que la integran, de forma separada; haciendo un análisis también, de las falencias que cada concepto deja frente a los procesos de las comunidades indígenas del país y sus planes de vida.

El concepto de ecodesarrollo (Sachs, 1981) busca definir la coevolución entre el campesinado, su forma de vida y la naturaleza, la relación con su entorno social y económico pero bajo la mirada profunda de un conocimiento funcional $y$ equilibrado de los ecosistemas que él interviene. Según su argumentación, son dos principios básicos los que rigen el término: un acceso social equilibrado a los recursos en el presente y una responsabilidad evolutiva natural a futuro con la misma naturaleza y con los seres humanos que deban hacer uso de los mismos mañana en condiciones similares.

La concepción de Sachs (1981) plantea actividades desde diferentes disciplinas, y termina dándole las bases a la agroecología para que surja con fuerza en los espacios campesinos, al concebir un nuevo formato de intervención del medio ambiente desde consideraciones culturales propias de la región, el uso de tecnologías de mínimo impacto, energías renovables, valoración del desarrollo de técnicas locales propias de las culturas que intervienen, etc., para responder a la crisis de la modernidad en el uso eficiente y equitativo de los recursos naturales. 
El concepto ecodesarrollo, sin embargo, no examina los ejercicios ancestrales históricos de la presencia de pueblos aborígenes en el territorio, donde los modelos de mercado, comercio, dinero, precio no representan un valor protagónico; ejemplo de ello son los indígenas del Pacífico colombiano en la región del departamento del Chocó en Colombia, en donde las valoraciones extrasensoriales, supranaturales, de creencias espirituales, están ligadas directamente con su mundo, un mundo enteramente natural; donde su espiritualidad está obligada a sus congéneres, ya sean animales o plantas unidos a los espíritus que según sus creencias cada uno de ellos contiene. Adicional, en esta zona lo que se menciona no solo pasa con los indígenas, también las comunidades afrodescendientes que habitan el territorio.

En palabras simples y a modo de ejemplo, se podría decir que: una disposición biológica, agropecuaria o alimentaria no es suficiente para desentramar los procederes de una comunidad indígena en su toma de decisiones sobre cuándo se consigue la comida, determinando el momento en que se caza, o en el cual se pesca, o se recolecta o se cosecha.

Un apoyo importante es la concepción de etnodesarrollo, que ajusta los faltantes del concepto de ecodesarrollo respecto a comunidades étnicas; es el concepto de etnodesarrollo, que Guillermo Bonfil (1995, p. 467) define:

Si por etnodesarrollo se entiende el ejercicio de la capacidad social de un pueblo para construir su futuro, aprovechando para ello las enseñanzas de su experiencia histórica y los recursos reales y potenciales de su cultura, de acuerdo con un proyecto que se defina según sus propios valores y aspiraciones; entonces, el proceso de etnodesarrollo exige el cumplimiento de un cierto número de condiciones o requisitos de diversa índole.

También es válido el aporte que se hace desde la etnoecología, que Toledo (2002) define como el estudio de los sistemas de conocimiento, prácticas y creencias que los diferentes grupos humanos tienen sobre su medio ambiente. $Y$ que para este caso compone un campo de estudio que aporta elementos sustanciales para un desarrollo endógeno más ajustado desde las comunidades indígenas del país. La consideración de que el término a usar era el de etnoecodesarrollo, se toma por su pertinencia y universo conceptual integrador, por ser innovador en las apreciaciones culturales y ancestrales, por la validación del conocimiento local como un conocimiento válido y científico, por el rescate inminente que se deben dar de los imaginarios colectivos de estrategias, manejos, valores y saberes locales para su propia organización (Leff, 2000). Así mismo, porque este toma fundamentos de los enfoques, metodologías, herramientas y apreciaciones de las definiciones de etnodesarrollo, etnoecología y ecodesarrollo, llevando el contexto mucho más allá de los ya considerados. En otros términos, una construcción 
desde las etnociencias, desde los principios de la diversidad cultural y de las formas diferenciadas de apropiación de la naturaleza (Leff, 2000).

\section{EL ETNOECODESARROLLO EN LOS PLANES DE VIDA INDÍGENA}

El discurso para definir lo que es un colombiano, se sustenta que este es más que un ciudadano de la nación, como lo define la Constitución Política de Colombia de 1991. Mejor es decir que es la expresión de la mezcla demográfica entre los amerindios presentes en el territorio y los europeos y africanos llegados en 1492; son zambos, mulatos, mestizos, castizos, moriscos, prietos, tresalbos... es un campesino, un indígena, un gitano, un afrodescendiente; o la mezcla de los tres, o los tres juntos. Por eso el rescate de las expresiones culturales tiene un alto valor cultural y político, así como de los conocimientos tradicionales, de los estilos de vida propios de comunidades étnicas en sus territorios, de los cultivos ancestrales, de las semillas criollas, de los estilos de agriculturas locales propias y de muchos saberes desconocidos, que todavía permanecen en la memoria histórica de muchos campesinos e indígenas (Leff, 2000), y aún se conciben como rescatables. Muchos pueblos indígenas en Colombia han iniciado un proceso de rescate de esta memoria, de esa herencia histórica de miles de años de construcción de conocimiento, en su constante ejercicio de ensayo en el acierto o el error (Monje, 2011).

Desde esta perspectiva, y tomando como fundamento los planteamientos de esta investigación sobre los modelos complejos de las estructuras étnicas, por su entramada relación en estos tipos de ecosociedades, donde los espacios de vida comunitaria representan un proceso de avanzada del ser humano en concordancia con el respeto que de ellos le merece la naturaleza y las definiciones de etnoecodesarrollo y las ciencias étnicas; y como ya se ha dicho antes, lo complejo de estos modelos de organización social y natural no radica en una estructura simple y siempre estática, sino más bien en los procesos dicientes hacia una constante retroalimentación entre los comportamientos naturales ecosistémicos y la información que de ella analiza el ser humano en sus espacios de vida. Se plantea que la particularidad de estos procesos radica en que el indígena hace lecturas permanentes de los espacios naturales y de sus componentes, determinando tiempos, cantidades, movilidades, caminos, utilidad y aprovechamiento de las especies que eran parte de su entorno. Estas lecturas siempre son revaloradas momento a momento, y les deja la mayor base informativa sobre los recursos que él utiliza y ha utilizado para sustentar su vida y mantener equilibrios casi armónicos muy cercanos a los procesos naturales.

Este tipo de comportamiento da paso a la trama que desde la agroecología le aporta la sociología del medio ambiente; lo complejo que nace en las relaciones naturales y sociales en un 
mismo espacio físico, permite cada vez más cerrar la brecha entre las sociedades culturales, entre los indígenas y los comportamientos de las especies en sus ecosistemas. Es decir, las coexistencias ecológicas y culturales se convirtieron en una práctica constante, revalorizada día a día y con una muy ajustada interpretación de quien hace uso de los recursos. En otras palabras, un papel ecológico de los indígenas en su medio natural de vida, sin desconocer su necesidad de consumo, de subsistencia y de evolución individual, grupal comunitaria y como especie.

Se define también que para la construcción permanente del concepto de etnoecodesarrollo desde la agroecología para los planes de vida indígena, se debe hablar de la economía ecológica; la que sin desconocer las construcciones hechas desde ya por los maestros de esta disciplina, plantea que los análisis sean tan flexibles, que no solo involucren los procesos de mercado sino también los procesos de apropiación para el consumo, con una revaloración de todos los productos en cualquier forma de trueque o modelo de mercado convencional y no convencional, cosechados, cazados, colectados o recibidos, y no como una representación de modelo simple de elementos de alimentación, vestido, materia prima o similar.

En este tipo de economías indígenas, los usos y apropiaciones de recursos no siempre tienen el mismo significado de uso. Para explicar este caso se toman dos ejemplos: el primero es cuando un integrante de una comunidad llega de una jornada de pesca con una considerable cantidad de pescado en una época donde no existe abundancia de este tipo de alimento; al llegar comparte su pescado con la comunidad sin que esto signifique un proceso diferente a un acto de compartir y donde cada uno irá a su casa a darle provecho a tan preciado regalo. Pero si el que llega es un cazador, quien en su recorrido ha obtenido un tatabro ${ }^{4}$, el proceso en la comunidad cambia totalmente, y se pasa de un simple compartir del ejercicio de los pescados a toda una fiesta de integración, donde todos hacen parte de la despresada, aliñada, adobado y preparación del cerdo en diferentes platos para hacer una gran comida comunitaria, ya que esto representa toda una simbología festiva.

Es decir, no todos los recursos tienen el mismo proceso de valor y aprecio, ya que para ellos algunos elementos representan toda una espiritualidad, diferente a otros que representan una simbología que puede ser cotidiana, de escasez o de abundancia. Lo que en verdad es cierto es que todo lo que tiene que ver con su alimentación, vestido o vivienda se debe abordar desde los enfoques de espiritualidad o simbología, para poder hacer un acercamiento a valores entendibles de los simples modelos económicos convencionales. Es decir, no se puede valorar tal cual este tipo de relaciones, porque para considerar un valor en dinero, su cuantificación crematística sería muy extraña, variable, y no se ajustaría a ningún modelo de mercado ni a algún ejercicio comercial convencional. 
Entonces, un plan de vida con relación a las estructuras de la economía ecológica, considerado como un ejercicio de etnoecodesarrollo, tendría tres componentes fundamentales: a) Su proceso complejo de vida; las consideraciones culturales y naturales de la zona de vida desde la recuperación de sus procesos culturales y respetos naturales ancestrales, estimando como fundamental su espiritualidad y simbología. b) Un proceso de organización social, de respeto natural, para definir sustentos de vida natural en una relación ecosocial y unos papeles de responsabilidad ecosistémica del pueblo indígena en su territorio. c) Una construcción básica de entendimiento de que sus recursos por difícil o fácil que sea su apropiación, colección, siembra o cosecha, tiene un valor y no un precio, y depende directamente de los equilibrios que dejen los dos puntos anteriores, para ser preservado y conservado en tiempo y espacio; sustentada ahí la pervivencia del pueblo indígena en sus zonas de vida.

\section{RESULTADOS}

Muchas de las aproximaciones que se tenían al respecto de la construcción de un plan de vida se orientaban desde todo punto de vista a los formatos planteados en las anteriores propuestas, los cuales buscaban construir un documento de enunciado y referencia sobre la cultura de cada una de las comunidades. Siempre las apreciaciones sobre el "quiénes somos", "qué queremos", "para dónde vamos", "cómo nos vemos", etc., hacían parte de los debates y discusiones en la construcción del mismo. Era estrictamente necesario dejar un documento escrito sobre estas premisas para poder tener una evidencia de la construcción de un plan de vida.

Adicional, un plan de vida según la política del Estado requiere ${ }^{5}$ tener un levantamiento topográfico del territorio, con el registro de las comunidades, determinando los límites, senderos, rutas, fuentes de agua, entre otros aspectos, a razón de radicar la titulación de un territorio colectivo para las comunidades asentadas; pero no era evidente en estas construcciones la razones sobre las cuales se determinaba ese territorio como el propio. Este ejercicio estaba fundamentado principalmente en la adjudicación de una titulación colectiva, de un territorio sobre el cual se moverían diferentes comunidades indígenas en su actividad cotidiana.

También es necesario considerar que gran parte del documento de plan de vida estaba enmarcado en las posibles acciones de inversión sobre las cuales se soportaría el uso de los recursos económicos procedentes de las transferencias de la Nación a los entes territoriales; y cómo a los territorios colectivos que aparecen figurados como entes territoriales les correspondía por ley acceder a ellos, ajustándose a las actividades políticoadministrativas de los municipios para que, a través de ellos, se reciban las transferencias de los recursos económicos, sin la posibilidad de definir canales más directos para este proceso 
entre la Nación y las comunidades indígenas contenidas en los resguardos.

El plan de vida o plan de desarrollo para comunidades étnicas buscaba definir una estructura "administrativa" sobre la cual descargar la responsabilidad del trámite ante el municipio, para hacerles efectiva la transferencia económica del Gobierno nacional y poder hacer uso de la misma. Acá nacen las figuras de los gobernadores indígenas como la cabeza administrativa de cada comunidad, de los alguaciles como las figuras de autoridad, de los vocales como los suplentes en los cargos, todos los anteriores con sus respectivos procesos de elección. Figuras que en ningún momento responden a la cultura indígena ancestral de ningún pueblo en la nación colombiana como autoridad.

Así mismo, en ningún espacio académico o de investigación se presenta un sustento epistemológico válido sobre las razones por las cuales los planes de vida debían construirse de esta manera; los argumentos siempre fueron fundamentados en el modelo económico y administrativo del Estado, en las jurisprudencias que se dictaban para ajustar la transición de la Constitución Política de Colombia de 1886 a la de 1991 -más de 100 años de vida política de la antigua Constitución-, y la inmersión por derecho de los pueblos que eran los habitantes naturales del territorio, pero presentes en una actualidad conflictiva con sus modelos de vida.

La organización indígena planteó en diferentes oportunidades estrategias para hacer una construcción más ajustada a lo cultural, que les permitiera a las comunidades tener una razón para iniciar un proceso de recuperación cultural y de organización local para la defensa y pervivencia de cada pueblo o nación indígena en su territorio (ONIC, 2010). Buscó de igual forma reducir la utilización de los recursos económicos llegados del Estado a través de las transferencias en la compra de materiales no funcionales a las comunidades o la acumulación masiva de elementos, máquinas, motores que no tendrían una vida útil con eficiencia en costo y tiempo de uso.

Un ejemplo de esto era el encontrar motores fuera de borda, casi nuevos, abandonados en una bodega por falta de mantenimiento, por una refacción que no se había comprado o por daños que ellos nunca valoraron y por ende nunca se recuperaron. Lo mismo ocurría con plantas eléctricas, computadoras, teléfonos satelitales, guadañadoras, y muchas otras cosas que se compraron por recomendación de alguien que en su momento quiso "modernizar" el estilo de vida o de la organización, en el nombre de la "calidad de vida".

Los primeros grandes gastos de las transferencias se quedaron en manos de lo "consultores" no indígenas o asesores profesionales que les ayudaron en la formulación de proyectos, y con quienes se trabajó la construcción de sus "planes de gastos" y la "planificación del territorio", y que estos mismos consultores luego convirtieron en el proceso que los indígenas habían ganado en la Constitución de 1991, en su forma de trabajar, de 
ganarse la vida, de hacer dinero. Se reconoce que a muchos de estos profesionales la influencia indígena los marcó, les hizo cambiar su forma de percibir la naturaleza de los pueblos indígenas en el país, y luego de la gran bonanza de dinero por las transferencias, se quedaron apoyando muchos procesos por menos dinero del que habían sido contratados en un principio.

El auge de estos procesos y del surgimiento de muchas experiencias organizativas, incrementó las ayudas provenientes de donantes internacionales. La cooperación internacional aportó muchos recursos para el fortalecimiento de las organizaciones indígenas en el país; las organizaciones nacionales, regionales y locales lograron parte de estas ayudas. Según el DAPS ${ }^{6}$, entre 1998 y 2004, el país recibió fondos por un valor de 1.300 millones de dólares en subvenciones, la mayor parte de estos recursos en la modalidad de no reembolsables.

Pero, ¿cómo usar adecuadamente estos recursos para responder a las coexistencias ecológicas y culturales de las comunidades indígenas en su territorio, en una práctica constante, revalorizada día a día, ajustada a la interpretación de quien hace uso de los recursos? Es difícil determinarlo desde las disciplinas convencionales, desde las consideraciones clásicas, desde las ciencias normales por la incertidumbre que se puede originar desde la periferia a los espacios indígenas (Funtowicz y Ravetz, 2000, p. 31), dejando una oportunidad para muchos espacios de estudio y trabajo; siendo esta una congruencia para buscar los sustentos epistemológicos sobre los cuales se pueda respaldar un plan de vida con enfoques diferentes a los institucionales.

La referencia primordial para encaminarse en la aventura de dicha congruencia se basa en que los indígenas en el país cumplen un papel ecológico en su medio natural de vida y subsistencia, sin desconocer su necesidad de consumo, evolución individual, grupal y como especie; especialmente porque el conocimiento está ligado a su historia como integrante en dicho espacio biofísico (Toledo y Barrera-Bassols, 2008). Consecuente con este planteamiento, se propone un abordaje particular para esta investigación, buscando en las disciplinas y ciencias que aportan a la agroecología los sustentáculos epistemológicos de los planes de vida, direccionando el trabajo desde premisas que responden a tres particularidades:

- Su universo indígena, que desde muchas razones ya expuestas, es particularmente complejo; y que es visto desde la integración natural del indígena al entorno en una dualidad de respeto naturaleza-hombre.

- Los formatos de ver, vivir, analizar, participar y compartir estas relaciones socioambientales de las comunidades en su medio de vida y no simplemente presentar un inventario o unas cuentas numéricas deterministas sobre lo que son, lo que hacen, lo que tienen, lo que proyectan, etc.; como quiera que para eso ya existen estudios que hacen referencia a estos datos y cuyos resultados se encuentran en otras investigaciones. 
- Su modelo de economía y comercio no convencional, los conceptos íntimos de valor y su inmersión parcial a los ejercicios crematísticos de los modelos comerciales, por las relaciones que generan con sus vecinos no indígenas.

La primera particularidad, con todas las exposiciones hechas en esta investigación, responde al sustento que da Morin (2007) en su obra, planteada desde las ligaciones que se hacen entre las estructuras mentales del ser, sus formas de proceder, sus percepciones extrasensoriales, su historia natural y social, su cultura y sus ritos, definiendo que este tipo de trabajos no se deben enmarcar en un fraccionamiento de conocimientos por las grandes limitantes que existen para entender estas comunidades; para entender las formas de relación con su entorno, el respeto particular e irrestricto por la vida en todas sus manifestaciones y las formas de equilibrio adaptadas en su transcurso de hábitat y consumo. En otras palabras, las dificultades en entender un mundo integrado, relacionado e interrelacionado, conectado e interconectado, dinámico y equilibrado, con funciones lógicas y extrasensoriales que responden a una cultura, a una razón de un ser indígena indivisible con la naturaleza en la que pervive.

El aporte de la complejidad que plantea Édgar Morin, es el de generar sustentos epistemológicos antagónicos a los sustentos planteados para la construcción de los planes de vida existentes. Entonces la complejidad se convierte en el sustento fundamental a considerar en la construcción de un plan de vida; ya que plantea que no solo se deben tener en cuenta en este proceso las estructuras sociales y naturales por separado; más bien observarla, plantearla y narrarla en un proceso complejo de coevolución natural y social en un espacio físico determinado -un territorio-.

La segunda particularidad, responde a lo planteado por Woodgate y Redclift (2002), referente a las relaciones socioambientales de los pueblos indígenas, con una teoría social incorporada a su evolución en el territorio, entendido esto como un aprendizaje conjunto en espacio y tiempo; reconociendo el vivir ecológico del indígena en la naturaleza y su papel como integrante de una sociedad excepcional, diferente y distante de las mismas concepciones de sociedad occidental. Es decir, un papel ecosocial, integrante de un medio natural e integrante de un grupo humano.

Este fundamento genera las bases para plantear que las ecosociedades, formadas en un proceso lento, observado y ensayado infinitas veces en pruebas de ensayo en acierto y error (Monje, 2011), son la base de trabajo para la preservación natural y el control del territorio desde lo ancestral ganado, frente a los planteamientos de conservación per se de los órganos de control y regulación ambiental del Estado, del mismo gobierno o de la sociedad civil sin distinción. Es decir, las políticas de parques naturales nacionales, zonas de reserva biológica, santuarios de fauna y flora o las reservas de la sociedad civil no pueden estar sobre la seguridad de la pervivencia de los pueblos 
o naciones indígenas que desde su proceso histórico y ancestral han habitado un territorio.

También desde este fundamento se valida la defensa de un territorio, sobre los intereses de macroproyectos, megaobras, explotaciones mineras y de hidrocarburos que atenten contra el control del territorio y la existencia de comunidades indígenas en sus ambientes sociales y culturales ancestrales (Monje, 2010). Esto es, que ni recurriendo a la consulta previa como derecho fundamental establecido en la Constitución Política de Colombia para las comunidades indígenas, se deba aceptar un proyecto de esta magnitud, ya que atenta contra la esencia de su existir en su territorio: su presencia histórica, la conservación natural y la pervivencia de un pueblo o nación indígena con sus principios fundamentales étnicos, culturales y ancestrales ${ }^{7}$.

La tercera particularidad se refiere específicamente a sus relaciones económicas y las formas tribales e ínter-tribales de practicarlas. La referencia específica de esta particularidad está basada en lo planteado por José Manuel Naredo (1996), donde el modelo económico de estas comunidades está ligado a su forma de pensar, vivir y relacionarse con su entorno tanto desde el espacio social como desde el ambiental. Sus modelos de intercambio se han ajustado evolutivamente a su relación con los no indígenas, se referencia entre ellos el valor sobre los productos de alimentación, de vestir, de las herramientas de trabajo y de transporte.

Las formas occidentales de valorar con dinero los procesos, materiales, objetos y trabajos tienen una aplicación parcial en sus vidas. El dinero tiene valor solo en los procesos en los que se relacionan con su entorno social no indígena, y generalmente en los centros poblados. No es común que en las comunidades exista dinero en efectivo, normalmente es muy poco o escaso ya que está determinado por la presencia o no presencia de no indígenas en su territorio. Ellos conjugan las formas primitivas de intercambios de materiales por materiales, trabajo por trabajo o cualquier de estas combinaciones que aplique según la necesidad de cada uno y no de la oferta; es decir, estos ejercicios están determinados en las necesidades que se generan y no de la capacidad de ofertar un bien o un servicio, en la figura del trueque, puede figurarse como la práctica del trueque, pero no es claro que para ellos signifique específicamente eso.

Existen retos que deja esta investigación a la economía ecológica, ya que estas relaciones de dar y recibir en todas sus magnitudes (Mauss, 1969), tienen inmersas también a las comunidades afrodescendientes vecinas de estas comunidades; involucrando también a los colonos no pertenecientes a ningún grupo étnico, quienes han ido llegando a estos territorios como habitantes permanentes en las cuatro últimas décadas, trascendiendo a que estas mismas personas tienen diferentes modos de relacionarse económicamente; unas en las comunidades, otras en los cultivos, otras en la selva, otras en el 
río y otras en los centros poblados con un comercio convencional más presente.

Pero pueden existir muchas otras disciplinas que logren aportar desde la agroecología a los sustentos epistemológicos de los planes de vida desde un enfoque más ajustado a la realidad indígena. Queda esbozado que desde estas tres premisas iníciales las comunidades indígenas pueden plantear sus planes de vida para que sean vistos más en un proceso a largo plazo, sin inmediatez administrativa, con fundamentos desde lo local y con respeto por sus ejes fundamentales de vida: la unidad, el territorio, la cultura y la autonomía.

Entonces, un plan de vida es una respuesta a la sustentabilidad de un proceso indígena, cuya base está fundamentada en una construcción permanente de sus espacios sociales y naturales, en ambientes justos para las partes inmersas en él, con respeto por sus construcciones sociales y culturales, no solo de parte de los no indígenas o de los entes del gobierno; también por parte de ellos mismos para lograr que se refleje en su realidad lo que día a día ellos construyen, y son la base de su propia historia con presencia autónoma en sus territorio, para pervivir, sostener, recuperar y resaltar su cultura, recuperar sus trabajos ancestrales y ser resistentes a la modernidad.

Todas estas consideraciones permitieron plantear el objetivo de que un plan de vida indígena se debe construir desde los instantes que conforman su cotidianidad, y que generalmente se les denomina momentos. Un momento del plan de vida se aproxima a un sentir específico del pueblo que le permite hacer una retrospectiva de su vida indígena en un territorio dentro de la gran nación. Unos con análisis y trabajos aproximados a la cosmovisión local de cada pueblo o nación indígena, por la ya presente erosión ancestral y cultural; otros, pensados y construidos por la comunidad que todavía posee gran parte de su historia, con rescate de algunos conocimientos que no se erosionan en su totalidad y que hacen parte importante de su rescate ancestral. Los momentos apuntan a las verdaderas razones de un plan de vida, básicamente a la forma como ellos desean relacionarse con las comunidades no indígenas y cómo quieren que se les reconozca, valore y respete.

Un momento para los planes de vida indígena se puede determinar como instantes históricos, culturales, ancestrales, singulares o particulares que hacen diferencia entre un pueblo y otro; y que en casi todos los pueblos y naciones indígenas marcan una gran diferencia con el restante cúmulo de población de la Nación. Un ejemplo de esto serían los conocimientos sobre sus espacios físicos, la relación de coexistencia con plantas y animales, es decir la memoria histórica biocultural grabada en sus hitos de vida y ligada a sus más profundas relaciones con su territorio (Toledo y Barrera-Bassols, 2008). Están marcados por sus recuerdos, sus modos y modelos de vida, de alimentación, las recordadas por los ancianos, las transmitidas en la tradición oral -muchas ya registradas en documentos escritos o audiovisuales-, que grafican una historia natural, de pervivencia, de acuerdo con sus valores ancestrales e históricos, con respeto 
y valoración de lo propio, lo que va mucho más allá de las técnicas; incluyendo nociones, percepciones e intuiciones de sus actuaciones en el momento presente, pero desde la visión ancestral cosmogónica indígena; por lo menos, la más recordada e implicada por sus propias interpretaciones de los imaginarios reales y soñados. Se identifican entonces cuatro momentos que se clasifican así:

Momento 1. La historia sobre su génesis: "el origen del pueblo Wounaan y unión al territorio ancestral". Misión de este momento: el uso ancestral de su territorio. Objetivo de este momento: hacer una delimitación del territorio, identificando sus fronteras físicas y ancestrales, identificando las relaciones con los vecinos, determinando los manejos de los mismos para ejercer una prevención del mal uso, procesos de sostenimiento y acciones de recuperación de fauna y flora asociada a su cultura.

Momento 2. La importancia de un solo núcleo social: "el núcleo social de unidad indígena como un pueblo o nación independiente". Misión: desarrollo del ejercicio de colectividad, unidad y sociedad indígena. Objetivo: observarse, reflexionar y consolidarse ellos mismos en su proceso como indígenas de una nación o un pueblo; no solo para obtener beneficios del Estado sino también como un ejercicio de autorreconocimiento del ser indígena como integrante de una ecosociedad, según los sustentos epistemológicos que en esta investigación se han planteado.

Momento 3. La autoridad y el control del territorio: "la autoridad tradicional como fundamento para el control ambiental, social y político del territorio". Misión: modos de uso de los conocimientos ancestrales, ejercidos y aplicados por las autoridades tradicionales para ejercer soberanía en su territorio y determinar su uso de acuerdo con su cultura y sus propios procesos de coevolución. Objetivo: desarrollar modelos de gobiernos propios, con identidad cultural, reconocimiento político, representativos en el espacio nacional con jerarquía y toma de decisiones sobre y en su territorio.

Momento 4. La transmisión del conocimiento: "el conocimiento tradicional como herencia de vida". Misión: transmisión del conocimiento tradicional, herencia cultural y control territorial en el rescate de las figuras tradicionales de autoridad. Objetivo: plantear un proceso de herencia cultural transmitida, para la conservación y revaloración de su historia, lengua, cultura y conocimientos ancestrales, en la educación tradicional y convencional, además establecer los procesos de heredad de los saberes históricos ligados a las autoridades tradicionales, medicina, espiritualidad y la guía por el sendero espiritual de su génesis ligada a un territorio.

Estos cuatro momentos responden en casi todos los espacios a sus estilos y procesos de vida, a las formas de relacionarse con su entorno, a las estructuras básicas que deben considerar como pueblo étnico al interior de un gran territorio. Responden también a la protección de unas formas de vida no convencionales que 
tienen grandes rivalidades con los procesos de modernidad, que permiten la existencia de un gran inventario natural en su entorno y que ponen un alto a muchos ejercicios de explotación de recursos naturales importantes para la conservación de biodiversidad, para ganancia de la misma Nación y de la vida en el planeta.

Queda expuesto que se pueden hacer ejercicios para revalorar si estos cuatro planteamientos responden a los momentos de otros pueblos indígenas en el país, pero es un ejercicio que se debe monitorear desde un nuevo enfoque; por lo que se hace necesario que una nueva investigación apoye a otros pueblos para colocar a prueba esta estructura de plan de vida, para valorar los resultados acá expuestos y para enriquecer o replantear este nuevo planteamiento epistemológico para los planes de vida desde la agroecología.

En este tejido, el plan de vida es un ejercicio participativo que involucra la voluntad política de una nación para la sustentación de un derecho social, para que comunidades bajo condiciones especiales de vida, territorio, condición étnica, conservación y recuperación puedan fijar los parámetros básicos de coevolución social y natural (Sevilla, 2007) en un espacio físico determinado, con una valoración real por lo cultural, por las evidencias ancestrales y las prácticas tradicionales.

Los logros más destacados en el caso del pueblo Wounaan del Bajo Baudó en la construcción de su plan de vida fueron específicamente:

- Logro 1: el establecimiento de los gobiernos tradicionales como gobiernos propios. Como una expresión de la autonomía dentro de cada territorio en su control y uso, respetando los procesos evolutivos en cada uno, valorados en sus contenidos culturales de cada comunidad en su cotidianidad como un colectivo y no como un proceso individual; representadas en las herencias de saberes, el valor por los estilos de espiritualidad y representatividad, determinando una participación permanente de todos y cada uno en el control del territorio, en el ejercicio de sus derechos individuales y colectivos, para el respeto del principio de autonomía e identidad.

- Logro 2: la reconstrucción de la estructura social propia. Donde el papel histórico de género y las relaciones naturales con su entorno son relevantes de acuerdo con sus hábitos culturales ancestrales; las comunidades son autónomas en la valoración de sus formas de vida, en sus procesos productivos y el uso de sus recursos naturales, en sus cambios y en su revalorización. Esta estructura es un ejercicio de participación, compartiendo los aciertos y los errores con el resto de las comunidades como ejercicio de cooperación en los congresos de asociación o cabildo mayor. Este respeto se extiende a las normas del Estado colombiano, que les acoge como ciudadanos y les considera como población en minoría étnica con derechos y deberes particulares y no generales de todo el Estado.

- Logro 3: el planteamiento de un proyecto político definido. Establecido y en ejecución como fuerza determinante en el hacer 
diario de los entes territoriales donde se represente la asociación o el cabildo mayor, con una visión común de los pueblos indígenas de la zona ante cualquier persona o entidad que quiera ver, apoyar o desarrollar actividades con ellos, en unidad de lenguaje, discurso, perspectiva y proyección política.

- Logro 4: la consideración de los momentos en la construcción de un plan de vida. La adopción de los cuatro momentos históricos resultado de este ejercicio para definir la estructura sobre la cual el trabajo del plan de vida se adopta como plan fundamental de pervivencia del pueblo Wounaan en su territorio ancestral del Bajo Baudó.

Los cuatro momentos de un plan de vida son un proceso constante de construcción, de alimentación, de compartir, un proceso permanente de integración de un pueblo o nación indígena al interior de sus funciones de identidad o como organización que agrupa a los pueblos indígenas de una zona, es un proceso participativo en su conformación y dirección, de acuerdo con los designios de las autoridades tradicionales de todas las comunidades asociadas, es un proceso constante de participación en la organización regional, y sus respectivos aportes; contribuyendo a la construcción nacional de las políticas y planes de la organización nacional como ente aglutinador de los pueblos y las naciones indígenas de Colombia. (Véase Figura 1).

Pero estos momentos no van solos o desligados de otros procesos; por el contrario, son el núcleo en el que se basa el trabajo de los pueblos indígenas en su plan de vida. Este centro de trabajo es cíclico, constante, y sin un orden lógico ya que responde a los momentos de un pueblo, a sus ancestros culturales, a sus espacios espirituales, a su territorio, a sus principios básicos de vida.

Alimenta principios rectores o puntos focales sobre los cuales se plantean muchos ejercicios que complementan su actuar como indígena en un Estado como Colombia. Bajo estos lineamientos o principios rectores que alimentan los momentos de un plan de vida se desarrollará la vida en un plan comunitario territorial, pero en conjunto de experiencias y unidad, en retroalimentación permanente, por la defensa del territorio habitado por ellos. Es un ejercicio local y comunitario por el sostenimiento y rescate de su cultura y por la defensa del derecho a la autonomía que les otorga la Constitución Política de Colombia en sus territorios. 


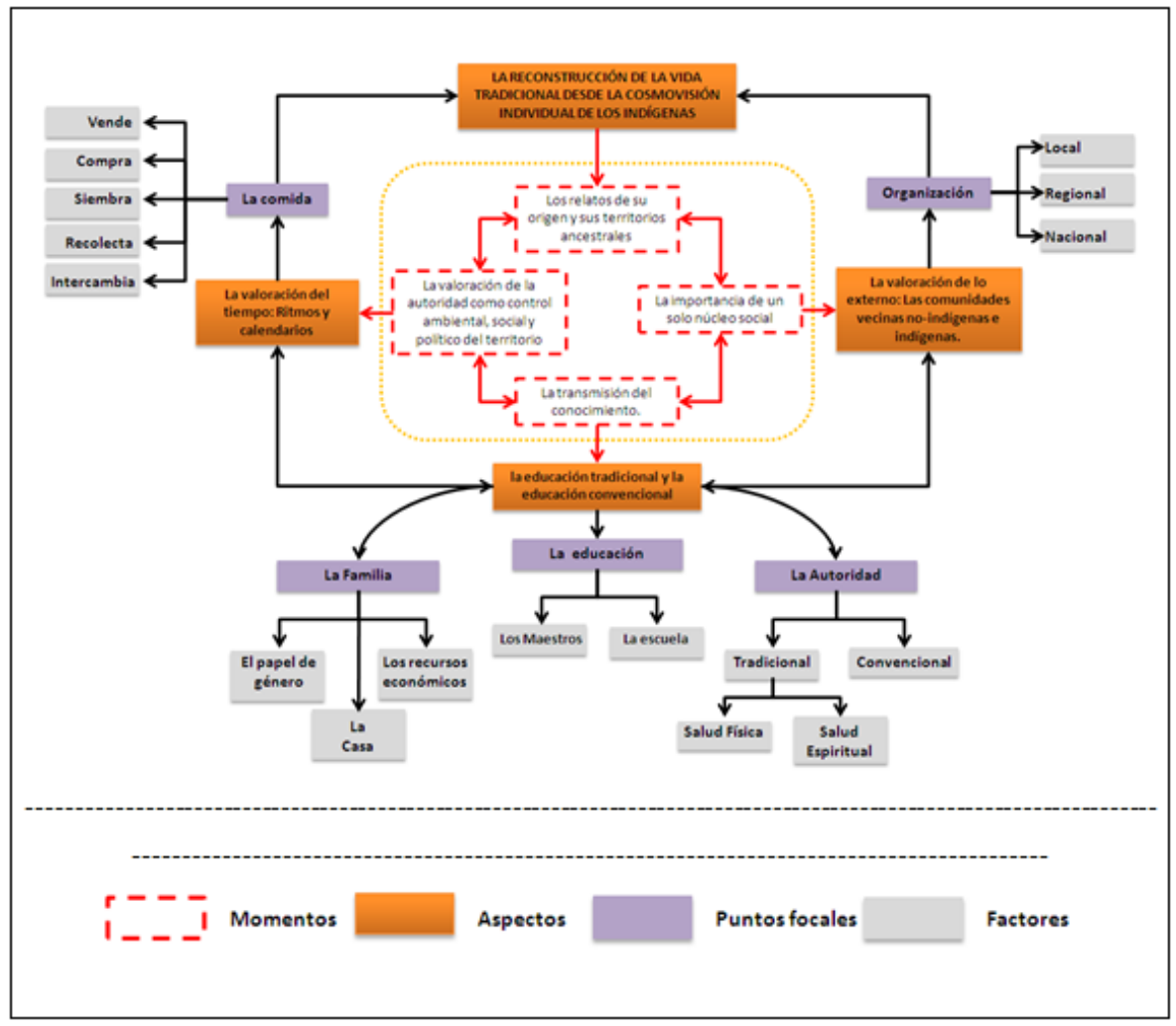

Fuente: construcción propia, febrero de 2012

Figura 1. Aproximación a la estructura funcional de un plan de vida a partir de los momentos

Hacer click sobre la imagen para ampliarla

Los puntos focales que subyacen y se alimentan de los cuatro momentos que conforman el ciclo en el núcleo son cinco: la comida, la familia, la educación, la autoridad y la organización. Sobre estos cualquier comunidad indígena tiene canales de contacto o relación con su mundo no indígena; los espacios en los cuales siempre pueden tener un contacto permanente, frecuente, temporal o fraccionado con sus vecinos, las comunidades afrodescendientes, los colonos, los entes regionales o nacionales, las ONGs, los investigadores, los visitantes, etc., en términos más situados a lo que se plantea por un plan de vida, son los puntos por los cuales los pueblos indígenas se relacionan con su exterior, con su entorno no indígena, porque se reconoce la importancia de las comunidades externas a los pueblos indígenas en su coevolución social y natural (Sevilla, 2007).

¿Por qué un plan de vida desde estas consideraciones es un plan de pervivencia y no una planeación económica o administrativa? Porque responde a elementos no considerados en los planes económicos administrativos, a elementos no valorados y que tienen conexión directa con su vida tradicional ancestral. Adicionalmente, un plan administrativo o un plan financiero es solo un componente ligado a uno de los puntos focales o principios rectores, marca una sola actividad: la de 
administrar y dar buen uso a las transferencias de dinero a que es merecedor por ser un ente territorial del Estado, y que por ley de la nación colombiana tiene derecho dentro del reparto nacional. Este mismo punto focal debe rendir y alimentar esos planes financieros administrativos anualmente, sin que sea la base de la vida en comunidad de un pueblo indígena; más bien, para que determine asignaciones presupuestales para apoyar el resto de actividades de los demás puntos focales.

¿Cómo funciona la estructura propuesta para los planes de vida? La base es que todo funcione en torno a los cuatro momentos de un plan de vida, que a partir de ahí y de acuerdo con las dinámicas comunitarias y de la organización indígena tomen como punto de partida la reconstrucción de su historia a partir de la memoria colectiva asociada, donde en unidades de diálogo se cuenten las historias registradas actualmente sobre su origen como pueblo indígena -momento uno-, teniendo un ejercicio consolidado que establezca si tienen puntos sobre su origen que no se ha documentado y que pueden determinar una riqueza ancestral mucho más completa.

Teniendo como fin la reconstrucción de su vida ancestral e histórica, el momento uno se convierte en la parte más importante y básica para trabajar los restantes momentos; es claro que no es un ejercicio definitivo ni totalitario, ya que la dinámica obliga a hacerlo de forma permanente para que las generaciones más jóvenes tengan una actividad constante de contacto con sus ancestros y con su historia ancestral.

Luego, se puede abordar cualquiera de los otros momentos; ellos respecto a su construcción pueden tener salidas a los puntos focales que determinan las relaciones con lo externo. El momento siguiente de trabajo es "la autoridad tradicional como fundamento para el control ambiental, social y político del territorio", a razón de que hipotéticamente en el momento inicial se determinó como lo más relevante la recuperación de la autoridad en el territorio; este momento da rutas para que este ejercicio, que implica relaciones con externos a las comunidades indígenas, pueda ser un elemento directriz del momento que lo contiene, específicamente en "a comida", entendida esta como un elemento constructor de relaciones externos, ya que existen varios procesos previos antes de que se haga presente en la mesa: cultivarla, recolectarla, intercambiarla, venderla o comprarla.

En este espacio específico existe todo un universo posterior a cada proceso. Si se vende tiene sus variables de venta, valores, precios, lugares de venta, personas que compran, etc.; es decir, que para este caso no solo se debe indicar que se hará con la comida, sino que también implica todo el proceso de relación que se da a través de ella. Esto determina que se deben considerar aspectos indígenas que no son muy comunes en las comunidades no indígenas, como los ritmos y los calendarios.

En el mismo ejemplo de la comida que se vende se requiere saber los periodos de abundancia, los momentos de corte, 
recolección o cosecha y los procesos para su transporte a los centros poblados o en su defecto a los espacios por los cuales quien los compra puede acceder a ellos y les represente una ganancia en las dos partes. Como se observa, no se trata solo de cosechar por cosechar, vender por vender o recolectar por recolectar; aquí también juega un papel importante sobre las consideraciones que se deben hacer y sobre si las dinámicas económicas les favorecen y no atentan con las dinámicas de los ritmos y calendarios establecidos por ellos.

Cada punto focal tiene una relación directa con una relación externa: la comida con el momento de la autoridad y el control del territorio, la organización con el momento de la importancia de un solo núcleo social; la familia, la autoridad y la educación con el momento de la transmisión del conocimiento.

Cada punto focal tiene una unidad de trabajo preliminar que determina la base sobre la cual se soporta; en este ejercicio, antes de llegar al punto focal se debe construir un sustento sobre el cómo se da el manejo del mismo, y las consideraciones que se deben hacer desde el plan de vida para poder hacer uso eficiente y pertinente. Para el caso de la comida el trabajo preliminar debe estar dado en la valoración del tiempo, los ritmos naturales y los calendarios indígenas; para el de la organización las consideraciones se deben hacer sobre la valoración de lo externo, las comunidades vecinas no indígenas e indígenas, en tanto que para el caso de la familia, la educación y la autoridad se debe considerar sobre el papel de la educación tradicional y la educación convencional.

Cada uno apunta a los factores que realmente tienen o pueden tener un contacto con lo externo y es determinante que se trabaje sobre el mismo para que realmente el proceso indígena tenga una fortaleza en su interior, logrando que estos contactos no alteren o tergiversen los enfoques de vida propios de sus culturas. Es claro que pueden llegar a surgir procesos de coevolución social y natural conjuntamente entre las comunidades inmersas en la zona indígena y no indígenas, pero esto es un proceso innato, el cual por simple dinámica social y natural se abre camino.

El contacto real con lo externo en cada punto focal se manifiesta así: para la comida, los ejercicios de venta, compra, siembra, recolección e intercambio. Para la familia se debe tener como referente el papel de género, la casa y los recursos económicos familiares; para la educación los nexos a tener en cuenta son los maestros y la escuela en su estructura funcional; para la autoridad los referentes son la autoridad tradicional -con dos subconsideraciones que se orientan respecto a los integrantes que sostienen cultural y ancestralmente la salud física, es decir, los médicos tradicionales y los que sostienen la salud espiritualy los requerimientos institucionales de la autoridad convencional; por último, la organización sostiene el contacto con lo externo por tres factores fundamentales en todo el proceso: la organización local, los procesos de organización regional y la organización que por derecho los debe aglutinar a todos en la Nación. 
Dependiendo de lo que se desee para un plan de vida y los resultados obtenidos al trabajar el Momento Uno -que es con el que siempre se debe iniciar-, se determina con cuál continuar esto por el grado de importancia o urgencia de abordar-. Desde ahí se hace necesario seguir el proceso hasta concluir el trabajo del momento que se aborde, hasta fijar las premisas para que los puntos focales y los factores de cada punto focal tengan una apreciación de regulación y forma de trabajo definido por la comunidad. No es necesario definir con cuál factor iniciar el trabajo, pero sí es importante que cada uno tenga en cuenta el Momento Uno para no ir en contra de los fundamentos sobre su origen y sus territorios ancestrales.

Es así como se construyen bases sobre las cuales un plan de vida tiene una estructura funcional dinámica multidimensional y con roles diferenciados, que no apunta solamente a una estrategia, sino más bien a muchas estrategias de un verdadero plan de vida. Y es acá donde la importancia de un solo núcleo social, en el punto focal de la organización -factor de lo localdetermina un plan de manejo financiero, de una proyección económica administrativa que responda a los requerimientos de los entes del gobierno encargados del control de estos procesos. Este ejercicio no está aislado del resto porque debe responder en las necesidades económicas a los otros puntos focales que requieren de esta planeación.

Al final, esta estructura da muchas más opciones para la construcción de un verdadero plan de vida, más ajustado a las realidades indígenas del país, a las realidades naturales de las relaciones que viven los indígenas con su medio y que responden también a las demandas hechas por los órganos del Gobierno nacional. No es una opción, es una alternativa de trabajo, no es un solo documento escrito, es una serie de documentos en muchos formatos -libros, manuales, cartillas, instructivos, estados financieros, plan de inversiones, etc.- que aportan para engranar los momentos del plan de vida; como referencia general se puede construir una guía o un pequeño documento rector que haga referencia al engranaje del resto de documentos del plan de vida.

\section{DISCUSIÓN DE RESULTADOS}

Luego del trabajo en campo y de la convivencia por largos y cortos espacios de tiempo entre las comunidades indígenas del país; en el Pacífico chocoano con comunidades Wounaan y Embera, en el Pacífico nariñense con comunidades Eperara Siapidara, con indígenas Coreguaje, Uititos, Ingas y Kamëntsá en el sur del país -alto, medio y bajo Caquetá, Putumayo e interior de Nariño-; con comunidades indígenas Wuanano, Desana, Piratapuyo, Kubea en el departamento del Vaupés; con indígenas artesanos Ticunas, Yaguas, Cocamas, Yucunas, Mirañas y Boras en el departamento del Amazonas, con indígenas Sálibas en el Casanare y Wayuu en el departamento de La Guajira; con el apoyo y las consideraciones sobre esta 
investigación logradas en pequeñas jornadas de trabajos, charlas informales, tertulias con integrantes de la ONIC, con estudiantes y amigos indígenas en la Corporación Universitaria Minuto de Dios - UNIMINUTO en Bogotá: se logra concluir este trabajo.

Una consideración preliminar sobre este trabajo es que no es un proceso concluido, ni sus apreciaciones y consideraciones son definitivas, más bien son un inicio. La construcción del documento completo de esta investigación tomó mucho más tiempo del esperado, por las reflexiones que se hacían sobre el mismo en cada consulta y en ocasiones por los momentos fluctuantes que se viven políticamente en el país y hacían que el perfil como se escribía ${ }^{8}$ cambiara; sin embargo, ya no es tiempo de temer a la crítica, porque de ella parte una nueva propuesta para continuar, y así será, o por lo menos así se espera.

La construcción del plan de vida para un pueblo o nación indígena en Colombia es relevante tanto política como socialmente, por todo lo que implica a nivel institucional en el Estado, más cuando está pensado para fijar las estrategias en el manejo de un territorio desde los umbrales propios de cada pueblo; y de allí que la formulación del mismo debe fundamentarse en los principios básicos de vida interna de cada pueblo involucrado en el plan.

La razón de construir un plan de vida indígena no es exactamente pesando en la redacción de un documento, un escrito o unas políticas determinadas; debe ser concebido como una reconstrucción de su vida en el territorio, en su cultura y en sus conocimientos, para fijar unas líneas estratégicas de fortalecimiento organizativo; que desde las actividades propias de cada comunidad, aporte en los lineamientos básicos rectores (Figura 2): la unidad como pueblo indígena, el territorio como unidad básica de vida y pervivencia, la cultura como el eje fundamental del sustento en la diferencia de estados de vida ${ }^{9}$, alimentación, salud, educación, espiritualidad y gobierno, y la autonomía como la capacidad de decidir sobre su territorio basado en los tres principios rectores anteriores. 


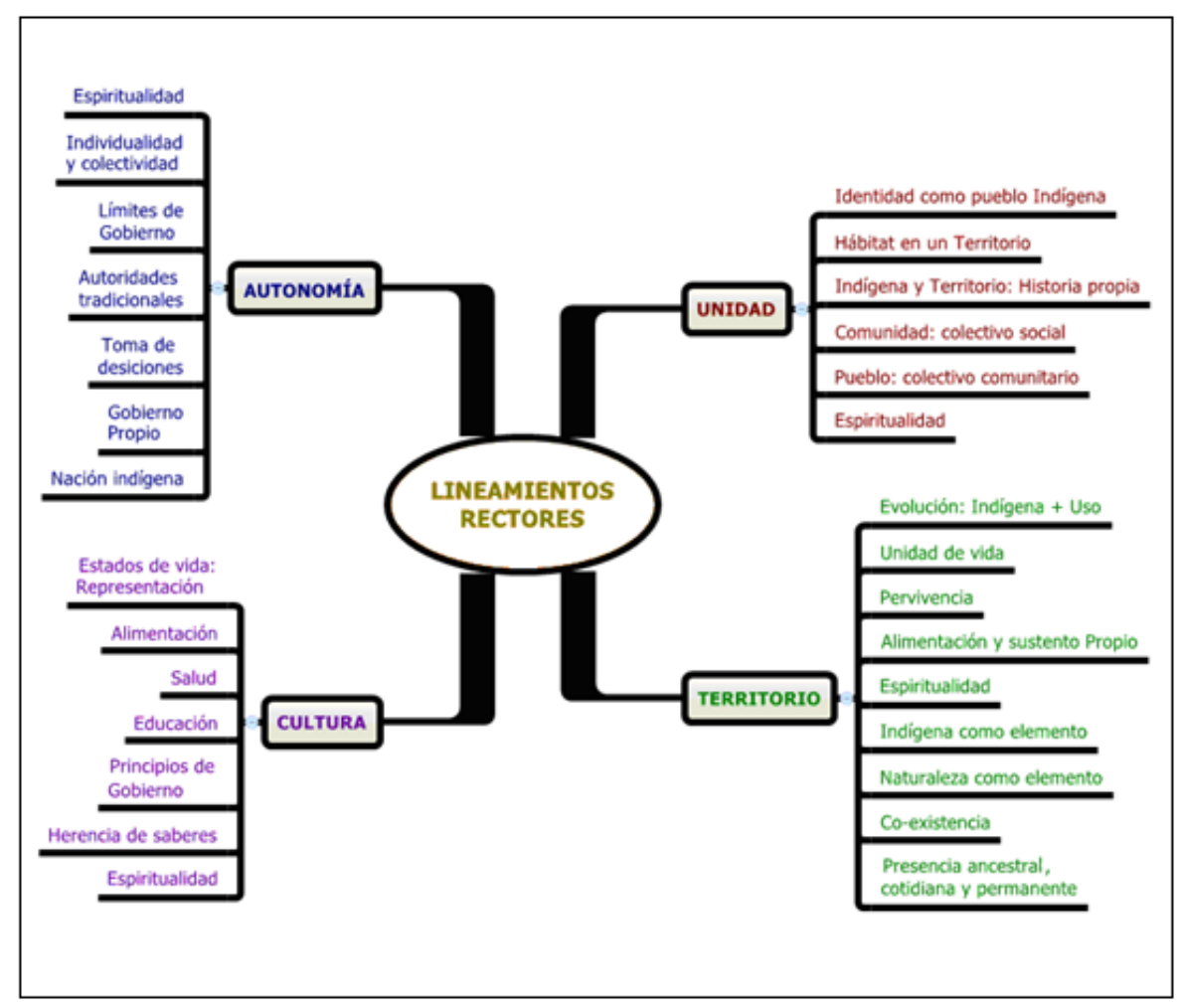

Fuente: elaboración propia (2008).

Figura 2. Lineamientos rectores del plan de vida. Hacer click sobre la imagen para ampliarla

La importancia del territorio y toda la ligación que se hace entre este y la autonomía indígena dictamina que sea la primera consideración para abordar una primera discusión. Este presupuesto se hace de forma cronológica, asumiendo puntos primordiales para que dicha conclusión quede bien planteada:

- Se considera como punto de partida el 12 de octubre de 1492. Respecto a esa fecha es necesario que el Estado colombiano reconozca públicamente que el encuentro de los dos mundos europeo y aborigen americano- determinó un fuerte fraccionamiento de las culturas aborígenes y europeas, iniciando un proceso de erosión cultural en las mismas; siendo las más perjudicadas las aborígenes americanas, por las inmensas pérdidas de personas, naciones, lenguas, manejos naturales y manejos de especies propias de las culturas amerindias, que repercuten en la realidad indígena del país hoy: una deuda no pagada.

- Es necesario reconocer que el territorio hoy habitado por la nación colombiana, fue ancestralmente habitado por indígenas, y por ende, ellos poseen una priorización de tierras y territorios sobre las acciones de empresas privadas, propietarios privados y la misma nación colombiana; que es la llamada a defender dichos territorios, porque en su gran mayoría son patrimonio natural e inmaterial del país y de las comunidades indígenas.

- Se debe reconocer que los indígenas son los directamente responsables de un buen uso de las zonas protegidas del país, que es bajo su anuencia que las unidades nacionales de zonas 
protegidas deben plantear su manejo, uso y conservación; entendiendo que dichas zonas poseen material vivo importante para la pervivencia de dichos pueblos. No es función del ente rector de los parques naturales el restringir el uso de animales, semillas, árboles o especies de importancia cultural o de alimentación a las comunidades indígenas; es función de los indígenas proponer actividades de manejo, veda, recuperación y repoblamiento, con la construcción de calendarios de abundancia como estrategia de uso y manejo sustentable de los recursos naturales de las zonas naturales, de interacción entre los indígenas, las zonas naturales y la unidad nacional de parques naturales.

- El principio de autonomía consagrado en la Constitución Política de Colombia es la base del reconocimiento que la nación le hace a sus pueblos ancestrales y se hace necesario que se reglamente adecuadamente, que se institucionalice y se le dé participación a todas las naciones indígenas para que aporten en la construcción de la jurisprudencia que le rija. Se debe tener como base las sentencias de la Corte Constitucional sobre el mismo, la inconstitucionalidad o vulneración de derechos fundamentales de las comunidades respecto a sus territorios y su derecho a opinar y definir acciones frente a su uso.

- El territorio es parte del universo indígena y el indígena es parte integral del territorio; su proceso es indivisible. No se concibe el territorio sin los indígenas, y un indígena obligatoriamente está ligado a su territorio; esta consideración aferra el concepto diferenciador entre indígena y campesino, marca el uso del territorio como eje fundamental de su pervivencia, de su vida; y no de su modelo o estilo de vida. El territorio figura un origen ancestral divino, localizado históricamente e identificado desde sus propios relatos de origen, habitación, uso y existencia. El territorio desde su concepción nunca será objeto de una negociación económica sobre su área o parte de su área, no se venderá y nunca se considerará como territorio a un espacio comprado, esto no es una actividad propia de los indígenas; por lo tanto, los territorios indígenas requieren un proceso especial para sus consideraciones administrativas referente al Estado y su función. Un ejemplo es lo sucedido respecto a los planes de ordenamiento territorial (POT), donde a través de la sentencia de la Corte Constitucional C-795 de 2000 se derogó la Ley 388 de 1997, teniendo como referente sobre los POT y las comunidades indígenas el principio de autonomía, dictaminando la inconstitucionalidad del mismo.

- No existe territorio si no existe un principio de autonomía; no es conducente un plan de vida sobre un territorio que no depende enteramente de la comunidad que lo habita; se consideran los pueblos indígenas como naciones culturalmente formadas, pero no se les da la acción de salvaguarda plena y se les somete a parcializaciones del manejo del mismo frente a intereses particulares, del Estado, de las empresas privadas; en todos los casos con lucros y explotaciones bien degradantes para el mismo territorio, su cultura y su vida.

Se reconoce entonces, que la nación colombiana presentó unos avances considerables, de gran cobertura y de alto impacto con la Constitución Política de 1991 frente a los argumentos pluriétnicos y multiculturales del territorio colombiano, su historia, 
su conformación social y política, sus expresiones culturales y sus arraigos culturales ancestrales. Se destacaron los preceptos políticos de respeto, reconocimiento y consideración de minoría, con ventajas políticas, de representación, de uso de los territorios, de funciones administrativas y de participación del reparto nacional; pero también estancó estos procesos, porque no legisló la funcionalidad de cada una de los principios fundamentales que la Constitución les otorgaba a estos grupos especiales de minorías étnicas.

También se evidencia que la legislación colombiana no ha cumplido ni medianamente con los grupos étnicos, sus expresiones y el espíritu de la norma máxima consagrada en la Constitución Política, presentando una contracción frente al espíritu constitucional construido en la Asamblea Nacional Constituyente iniciada el 4 de julio de 1991. La no reglamentación de los derechos fundamentales consagrados en la Carta Magna para las minorías étnicas, ha hecho que se tenga que acudir constantemente al estamento constitucional ${ }^{10}$ para la defensa de los mismos; presentando escenarios de irrespeto, violación, manipulación y despojo de dichos derechos a los pueblos indígenas, afrodescendientes y gitanos, considerados como pueblos en minoría étnica.

No existe una legislación, ni reglamentación que permita sustentar un proceso real frente a la adopción de planes de vida como elemento fundamental de valor, que permita a una nación indígena defender su derecho a la consulta previa, a la decisión del uso del territorio y la no adopción de políticas o proyectos que afecten su condición de pueblo indígena, pero sí es posible plantear una unidad de trabajo, con un proceso clarificado desde la organización indígena, que se oriente a la construcción de planes de vida que perduren en el tiempo, que se reconozcan ante las instituciones, que determinen que los planes financieros son una parte del plan de vida que se puede actualizar permanentemente, y que de este no depende que el plan se cumpla en su espíritu.

Se reconoce también que un plan de vida, consolidado a partir de la organización indígena como elemento unificador desde la diferencia cultural, de territorio, de lengua, de consideración ancestral, es la base sobre la cual la nación colombiana se obliga a legislar desde la participación sobre los derechos adquiridos políticamente por estas comunidades en la Constitución de 1991. Si un plan de vida es mucho más que un proceso de manejo económico, obliga a que los mismos indígenas se vean como lo que les reconoce la CPC: una gran nación cultural y originaria del territorio que habitan. Que se vean como la salvaguarda de la historia natural y ancestral de la gran nación, que por diferentes razones hoy se llama Colombia y los agrupa tanto política como en identidad nacional.

Este argumento, sustenta y da bases para que se puede hacer un plan de vida mucho más amplio para dejar el manejo económico a las unidades contenidas en uno de los momentos que lo determinan; tendientes a que los planes de vida cuenten 
con el ítem económico y no al contrario, es decir, que los procesos administrativos del Estado no obstaculicen la permanente aplicación de un plan de vida indígena y que esté en función del mismo y no al revés. El pendiente en esta conclusión queda expuesto a la necesidad imperante para que desde la organización nacional indígena se determine un proceso articulador de los planes de vida, desde las consideraciones que deben ir más allá de un manejo, de un planteamiento de organización y de echar raíces en su territorio, en su cultura, en la defensa de su autonomía y la unidad como pueblo indígena de la gran nación colombiana.

En el epílogo de esta conclusión queda la atención a dar cumplimiento a una solicitud real para que los planes de vida estén mucho más allá de la simple concepción, ajustados a la realidad indígena y no de una construcción meramente teórica, que puede ser una historia para contar, una canción para cantar, una pintura para pintar o toda expresión natural y cultural a la vez, que permita que cada plan de vida indígena, sea conocido en los pueblos o comunidades involucradas, desde el más pequeño hasta el más anciano; para que lo ayuden a construir constantemente y lo defiendan; porque no puede ser estático, ya que despierta mucho más allá de los sentidos; despierta los mundos espirituales, que muy seguramente alimentarán por intermedio de sus comunicadores vivos, la reconstrucción de su mundo indígena.

\section{REFERENCIAS}

- Bonfil Batalla, G. (1995). Etnodesarrollo: sus premisas jurídicas, políticas y de organización. En Bonfil Batalla, G., Obras escogidas de Guillermo Bonfil Batalla. Vol. II. (pp. 464-480). México: INAH I INI.

- DANE. (2000). Los grupos étnicos de Colombia en el censo de 1993 - Análisis de Resultados. Bogotá: Autor.

- _ _ (2005). Censo general 2005 - nivel nacional. Bogotá: Autor

- Fals B., O. (1975). Historia de la cuestión agraria en Colombia. Bogotá: Fundación Rosca de investigación y acción.

- Funtowicz, S.O. y Ravetz, J R. (2000). La Ciencia posnormal: la ciencia con la gente. Barcelona: Icaria Editores.

- Leff, E. (2000). Saber ambiental. Sustentabilidad, racionalidad, complejidad y poder. Ciudad de México, México: Siglo XXI Editores.

- Mauss, M. (1969). Ensayo sobre el don: Forma y función del intercambio en las sociedades arcaicas. París: Fuvres iii.

- Monje Carvajal, J.J. (2010). El ecoetnodesarrollo en las comunidades indígenas en Colombia, una descripción histórica para descubrir las verdades y mentiras sobre su autonomía. Inventum, 7, 38-43.

- . (2011). La agroecología, un marco de referencia para entender sus procesos en la investigación y la praxis. Luna Azul, $32,50-67$. 
- Morin, E. (2007). Introducción al pensamiento complejo. Barcelona: Gedisa.

- Naredo, J.M. (1996). La economía en evolución. Historia y perspectivas de las categorías básicas del pensamiento económico. Madrid: Siglo XXI.

- ONIC. (2010). Palabra dulce, aire de vida. Forjando caminos para la pervivencia de los pueblos indígenas en riesgo de extinción en Colombia. Bogotá: Autor.

- Sachs, I. (1981). Ecodesarrollo: concepto, aplicación, beneficios y riesgos. Agricultura y sociedad, 18, 9-32.

- Sevilla Guzmán, E. (2007). De la sociología rural a la agroecología. Barcelona: Icaria.

- Toledo Manzur, V.M. (2002). Ethnoecology: a conceptual framework for the study of indigenous knowledge of nature. Ethnobiology and Biocultural Diversity, 511-522.

- Toledo Manzur, V.M. y Barrera-Bassols, N. (2008). La memoria biocultural. La importancia ecológica de las sabidurías tradicionales. Barcelona: Icaria Editorial.

- Woodgate, G. y Redclift, M. (2002). Sociología del medio ambiente. Una perspectiva internacional. Madrid: McGrawHill/Interamericana de España.

1. Ingeniero Agroecólogo de la Universidad de la Amazonia. Máster en Agroecología, Sociología y Desarrollo Rural de la Universidad Internacional de Andalucía. Doctorado en Agroecología, Sociología y Desarrollo Rural Sostenible de la Universidad de Córdoba, España. Profesor de planta de la Corporación Universitaria Minuto de Dios, director del programa de Ingeniería Agroecológica. jmonje@uniminuto.edu / jhonmonje@yahoo.es

2. Constitución Política de Colombia, art. 246.

3. Esta es una referencia del Ministerio del Interior, de la oficina de etnias, y que solo reúne a las comunidades de las cuales esta entidad tiene registro por los recursos económicos que pone en las transferencias para los territorios colectivos, pero difiere de la cifra de la ONIC, que en 2010 estimó que existen 102 pueblos indígenas.

4. Cerdo de monte (Tayassu albirostris).

5. Como referencia obligatoria del Ministerio del Interior, de la oficina de etnias.

6. Departamento Administrativo para la Prosperidad Social -DAPS-, la entidad del Gobierno nacional que encabeza el sector de inclusión social y reconciliación, al cual se encuentran adscritas las siguientes entidades: Agencia Nacional para la Superación de la Pobreza Extrema -ANSPE-, Unidad de Atención y Reparación Integral a las Víctimas, Unidad Administrativa Especial para la Consolidación Territorial, Instituto Colombiano de Bienestar Familiar -ICBF- y Centro de Memoria Histórica.

7. Como está considerado en el Capítulo 4 de este documento sobre los ejes rectores que guían las actuaciones de los autogobiernos para su principio de autonomía.

8. Este documento, aunque no está escrito como una manifestación o denuncia, es una pequeña muestra sobre el momento real que se vive en las comunidades indígenas y su organización; por los diferentes factores de violencia a los que están constantemente 
sometidos, a las políticas cambiantes que los hace cada día estar más a la deriva en una nación tan benevolente y acomodada a los planteamientos de la globalización y no a atender las demandas internas de sus habitantes. Es una crítica pura desde la razón indígena con los ojos de un habitante común de una nación que se vanagloria de su riqueza étnica, pero que la maltrata al no darle la importancia que debe tener; que crea políticas constitucionales que les da un estatus de respeto, pero que los irrespeta consecuentemente en el accionar industrial, de desarrollo, de modelos económicos, de permisos de explotación que transgreden su cultura y sus territorios, tan suave y estratégicamente trazadas que se hacen casi que invisibles hacía el exterior; por eso este documento está escrito en estos tonos, matizados de romanticismo y dolor, de esperanza y protesta, de propuesta y resignación.

9. Se refiere a las formas de vida diferenciadas en cada comunidad, a los papeles negociados e históricos entre los papeles de género, de desempeño, de tiempos, de ocupación, de uso del territorio, etc.

10. La Corte Constitucional fue creada en el mismo proceso, para velar por el cumplimiento del espíritu de la norma, la validez de la misma y la defensa de los derechos legalmente amparados por esta.

Para citar este artículo: Monje Carvajal, J.J. (2014). El plan de vida de los pueblos indígenas de Colombia, una construcción de etnoecodesarrollo. Revista Luna Azul, 41, 29-56. Recuperado de http://lunazul.ucaldas.edu.co/index.php?option=content\&tas k=view\&id=1054 